\title{
Changes in Depression and Stress after Release from a Tobacco-Free Prison in the United States
}

\author{
Jacob J. van den Berg ${ }^{1, *}$, Mary B. Roberts ${ }^{2}$, Beth C. Bock ${ }^{3}$, Rosemarie A. Martin ${ }^{4}$, L.A.R. Stein ${ }^{5}$, \\ Donna R. Parker ${ }^{2}$, Arthur R. McGovern ${ }^{6}$, Sarah Hart Shuford ${ }^{7}$ and Jennifer G. Clarke ${ }^{2}$
}

Received: 4 November 2015; Accepted: 6 January 2016; Published: 12 January 2016

Academic Editor: Deborah Shelton

1 Division of Infectious Diseases, The Miriam Hospital, 164 Summit Avenue, Providence, RI 02906, USA

2 Center for Primary Care and Prevention, Memorial Hospital of Rhode Island, 111 Brewster Street,

Pawtucket, RI 02860, USA; Mary_Roberts@mhri.org (M.B.R.); Donna_Parker@brown.edu (D.R.P.);

Jennifer_Clarke@brown.edu (J.G.C.)

3 Centers for Behavioral \& Preventive Medicine, The Miriam Hospital, Coro West, Suite 309, 164 Summit Avenue, Providence, RI 02906, USA; Beth_Bock@brown.edu

4 Department of Behavioral and Social Sciences, Brown University School of Public Health, Box G-S121-4, Providence, RI 02912, USA; Rosemarie_Martin@brown.edu

5 Department of Psychology, University of Rhode Island, Chafee Hall, 142 Flagg Road, Kingston, RI 02881, USA; LARStein@uri.edu

6 Department of Psychology, Nichols College, 129 Center Road, Dudley, MA 01571, USA; Arthur.McGovern@nichols.edu

7 Brown University School of Public Health, 121 South Main Street, Providence, RI 02912, USA; Sarah_Shuford@brown.edu

* Correspondence: Jacob_Vandenberg@brown.edu; Tel.: +1-401-793-8227; Fax: +1-401-793-8165

\begin{abstract}
Prior research has found high levels of depression and stress among persons who are incarcerated in the United States (U.S.). However, little is known about changes in depression and stress levels among inmates post-incarceration. The aim of this study was to examine changes in levels of depression and stress during and after incarceration in a tobacco-free facility. Questionnaires that included valid and reliable measures of depression and stress were completed by 208 male and female inmates approximately eight weeks before and three weeks after release from a northeastern U.S. prison. Although most inmates improved after prison, $30.8 \%$ had a worsening in levels of depression between baseline and the three-week follow-up. In addition, $29.8 \%$ had a worsening in levels of stress after release than during incarceration. While it is not surprising that the majority of inmates reported lower levels of depression and stress post-incarceration, a sizable minority had an increase in symptoms, suggesting that environmental stressors may be worse in the community than in prison for some inmates. Further research is needed to address depression and stress levels during and after incarceration in order for inmates to have a healthier transition back into the community and to prevent repeat incarcerations.
\end{abstract}

Keywords: depression; stress; prisoners; post-release; United States

\section{Introduction}

In the United States (U.S.), over 2.2 million people are currently incarcerated [1]. Increasingly, those with mental health problems are disproportionately represented in prisons and jails in America [2]. Each year, approximately 700,000 persons (approximately 32\%) with mental illness are admitted to U.S. correctional facilities. In addition, an estimated $56 \%$ of state prisoners, $45 \%$ of federal prisoners, and $64 \%$ of jail inmates in the U.S. reported having a recent history or symptoms of a mental health 
problem that occurred in the past year [3]. Indeed, it has been noted that correctional facilities currently house more persons with severe mental illness than in state hospitals throughout the country [4].

Depression and stress are particularly common among persons who are incarcerated in the U.S. [3]. Depression is characterized by "sadness, loss of interest or pleasure, feelings of guilt or low self-worth, disturbed sleep or appetite, feelings of tiredness, and poor concentration that is long-lasting or recurrent" [5]. In contrast, stress is defined as "a particular relationship between the person and the environment that is appraised by the person as taxing or exceeding his or her resources and endangering his or her well-being" [6]. The psychological effects of imprisonment and its implications for post-release contribute to inmates' experience of both depression and stress during and after incarceration [7].

While much research indicates that risk for depression is influenced by both genetics and environmental factors, trauma, difficult life circumstances, or any stressful situation, such as incarceration, may trigger a major depressive episode [8]. For example, researchers in one study found that more than $40 \%$ of people recruited from a hospital's emergency room in Israel with post-traumatic stress disorder also had depression four months after the traumatic event [9]. In the general population, there is also increasing evidence that chronic stressful life events coupled with poor coping strategies can increase the risk of developing depression and physical illnesses [10-12].

Little is known about changes in levels of depression and stress among inmates during incarceration and post-release. Examining changes in depression and stress levels among inmates during and after incarceration is particularly important as it could help us understand how to better assist inmates during the post-release reintegration process and to prevent repeat incarcerations. The current study focuses on investigating changes in depression and stress levels as inmates are released from prison and return back to the community. We hypothesized that depression and stress levels among inmates would mostly improve post-incarceration but that because of challenges associated with release to the community (e.g., obtaining housing, reestablishing connection with family and friends, securing income) some individuals may experience a worsening of symptoms. We were also interested in identifying what factors might impact differences in depression and stress levels according to specific demographic characteristics, including age, gender, race/ethnicity, education, annual income (prior to incarceration), length of incarceration, and living situation.

\section{Methods}

\subsection{Data Collection}

Data were drawn from the randomized controlled trial (RCT), "Project WISE" (Working Inside for Smoking Elimination), that investigated a smoking abstinence intervention conducted in a tobacco-free prison (cigarette smoking and the use of other tobacco products are not permitted in or around premises by inmates or staff) located in the northeastern U.S. $[13,14]$. The RCT evaluated the effectiveness of a six-session integrated cognitive-behavioral therapy and motivational interviewing intervention in comparison to a general wellness control condition that included viewing health videos that did not include mental health as a topic of discussion. The frequency and duration of participant contact between both conditions were equivalent. The RCT was reviewed and approved by the Memorial Hospital of Rhode Island Institutional Review Board and the Medical Research Advisory Group at the Rhode Island Department of Corrections (Office for Human Research Protection Federal Wide Assurance\# for Memorial Hospital of Rhode Island is 00000346). In addition, a Certificate of Confidentiality was obtained to further ensure participant privacy.

Inclusion criteria for Project WISE required that inmates had to be $\geqslant 18$ years old, report smoking ten or more cigarettes per day prior to incarceration, be able to communicate in English, and be scheduled for release from prison within eight weeks of study enrollment. Exclusion criteria were inability to give informed consent or housed in a segregation unit as there was limited access to these particular inmates due to their current status. Symptoms of depression resulting from cigarette 
smoking cessation were not a concern as the average length of time since their last cigarette was seven months, suggesting that withdrawal symptoms due to quitting cigarette smoking would have likely subsided by that point for the majority of inmates who participated in the current study. All eligible inmates who were interested in participating reviewed and signed the informed consent document administered by trained research staff.

Of the 312 inmates screened during the RCT, 273 met study eligibility and 262 agreed to participate and were consented. Baseline data $(n=247)$ were excluded from a total of 19 participants (nine whose data were lost due to a computer program error, six who became ineligible for the study after the baseline because they were never released from prison, and four who had missing data on the 10-item Center for Epidemiologic Studies Depression Scale (CES-D-10) that measures self-reported depression $[15,16]$.) At the three-week follow-up $(n=220)$ an additional 12 participants were excluded due to a significant amount of missing data on the CES-D-10 and/or the 10-item Perceived Stress Scale (PSS) the measures self-reported stress [17]. The final total sample for the current study was 208, representing a response rate of $84.2 \%$ of the baseline sample.

\subsection{Variables}

Participants completed a 60-min Audio Computer-Assisted Self-Interview at baseline pre-release and at three weeks post-release.

Depression levels were assessed using the CES-D-10 [15]. Participants indicated how often in the past week they experienced specific feelings or behaviors on a 4-point Likert-type scale $(0=$ rarely or none of the time (less than one day) to $3=$ all of the time (5-7 days)). Sample items include: "I felt depressed," "My sleep was restless," and "I felt lonely." Specific items are reversed scored and all items are summed to provide an overall score ranging from 0 to 30 with higher scores indicating greater levels of depression. A score of 0-9 is "no depression", a score of 10-14 is "mild depression", a score of 15 or greater is "severe depression." Internal consistency (Cronbach's alpha $=0.86$ ) and test-retest reliability for the CES-D-10 has been reported to be excellent [16]. In the current study, Cronbach's alpha for the CES-D-10 was 0.84 .

Stress levels were measured using the PSS [17]. Items, such as "In the last month, how often have you been upset because of something that happened unexpectedly?", were rated by participants to indicate how often they felt or thought a certain way using a five-point Likert-type scale ranging from 0 (never) to 4 (very often). Specific items are reversed scored and item ratings are averaged with higher scores indicative of greater levels of perceived stress. A score of 0-13 is "no stress", a score of 14-19 is "mild stress", and a score of 20 or greater is "severe stress." The total score Cronbach's alpha for the PSS was 0.81 in this study.

Demographic characteristics included age, gender, race/ethnicity, education, annual income (prior to incarceration), length of incarceration, and living situation. A stable living situation was defined as living with a sexual partner, children, parents, other family, alone or with friends at the participant's residence. An unstable living situation was defined as living with friends at the friend's residence, shelter, on the street, or in a controlled environment.

Perceived physical health was assessed by asking participants to indicate how healthy they considered themselves to be rated as "excellent", "very good", "good", or "poor."

\subsection{Data Analysis}

IBM SPSS Statistics for Windows (version 20) was used to perform all statistical analyses. Demographic characteristics were calculated using descriptive statistics including frequencies, means, and standard deviations. Change in depression and stress were calculated for each scale separately by subtracting the baseline score from the three-week follow-up score. Positive difference values indicated worsened depression or stress and negative difference values indicated improved depression or stress. Each participant was coded as either improved or worsened for depression or stress. We compared those with improved $v s$. worsened depression and stress levels on demographic characteristics 
including age, gender (coded Male vs. Female), race/ethnicity (coded White, non-Hispanic; Hispanic; Black, non-Hispanic; and Other, non-Hispanic), education (coded $<$ High School vs. High School or greater), annual income (coded $<\$ 20,000 /$ year), length of incarceration (coded 6 months or less $v s$. more than 6 months), and living situation (coded stable vs. unstable) with chi-square analyses for categorical variables and independent $t$-tests for continuous variables. We conducted analyses to determine if there were differences between those participants who worsened and those participants who improved with respect to depression and stress levels from baseline to three-week follow-up. We hypothesized that the majority of participants would improve in stress and depression after release from incarceration, but that some participants may have an exacerbation of symptoms due to release to the community.

\section{Results}

\subsection{Excluded/Included Participants}

Excluded participants were those lost at three-week follow-up $(n=27)$ and those who were missing a portion of the assessment that included CES-D-10 and/or PSS $(n=12)$. No significant differences were found between those participants included $(n=208,84.2 \%)$ and those excluded $(n=39,15.8 \%)$ in age, race, education, and living environment. In comparison to excluded participants, participants included in the analyses had a higher monthly income prior to incarceration $(M=\$ 450$, $S D=\$ 684$ vs. $M=\$ 1753, S D=\$ 4904, \mathrm{t}(213)=-3.43, p=0.001)$ and had a higher percentage who were incarcerated longer than six months ( $\left.34 \% v s .55 \%, \chi^{2}=5.74, \mathrm{df}=1, p=0.02\right)$. None of the demographic characteristics were significantly related to change in CES-D-10 or PSS scores between baseline and three-week follow-up.

\subsection{Descriptive Analysis for Final Sample}

The majority of the final sample $(n=208)$ was $66.8 \%(n=139)$ men with a mean age of 35.4 years $(S D=9.2)$. Fifty point nine percent $(n=106)$ self-identified as White, $18.3 \%(n=38)$ as Black, and $30.7 \%$ $(n=66)$ as Multiracial/Other. In addition, $20.2 \%(n=42)$ self-identified as Hispanic. Sixty-four point nine percent $(n=135)$ also had less than 12 years of formal education. The median annual income $\$ 7200$ (inter-quartile range $(\mathrm{IQR})=\$ 15,600)$ and length of incarceration was 7.5 months (IQR $=18$ months). Seventy-one point six $(n=149)$ percent of the sample reported living in a stable living environment prior to incarceration.

\subsection{Depression and Stress Levels at Baseline and Three-Week Follow-Up}

At baseline, 36.1\% ( $n=75)$ of participants had no depression (CES-D-10 score $0-9), 31.3 \%(n=65)$ had mild depression (CES-D-10 score 10-14), and 32.7\% $(n=68)$ had severe depression (CES-D-10 score of 15 or greater). Three weeks after release from prison, $58.2 \%(n=121)$ had no depression, $21.6 \%(n=45)$ had mild depression, and $20.2 \%(n=42)$ had severe depression. The average baseline, three-week follow-up, and difference between baseline and follow-up CES-D-10 scores were $12.4(S D=6.3)$, $9.1(S D=5.9)$, and $3.3(S D=6.8)$, respectively. While $69.2 \%(n=144)$ of participants improved, $30.8 \%$ $(n=64)$ had a worsening in their CES-D-10 score between baseline and the three-week follow-up.

At baseline, 31.7\% $(n=66)$ of participants had no stress or mild stress (PSS score $0-19)$ and $68.3 \%$ $(n=142)$ had severe stress (PSS score $20-40)$. Three weeks after release from prison, $57.7 \%(n=120)$ had mild or no stress and $42.3 \%(n=88)$ had severe stress. The average baseline, three-week follow-up, and difference between baseline and follow-up PSS scores were $21.9(S D=6.2), 17.6(S D=5.6)$, and 4.3 $(S D=7.4)$, respectively. While $70.2 \%(n=146)$ of participants' stress improved, $29.8 \%(n=62)$ had worse PSS scores after release than before release. The percentage of participants who had both depression and stress at baseline and three-week follow-up was $55.3 \%(n=115)$ and $32.7 \%(n=68)$, respectively. 


\subsection{Differences between Those Who Improved vs. Those Who Worsened in Depression and Stress}

Significant differences were found between those participants who worsened and those who improved in depression and stress scores from baseline to three-week follow-up. Table 1 presents the group differences based on depression scores (improved $v s$. worsened) and Table 2 presents the group differences based on stress scores (improved vs. worsened). In comparison to those participants who improved, those who worsened in depression at the three-week follow-up were more likely to report an annual income of $\$ 20,000$ or less $(92.7 \%, n=76$ vs. $76.1 \%, n=89)$ and identify their physical health status as poor/fair/good vs. very good/excellent ( $56.4 \%, n=22$ vs. $43.6 \%, n=17)$. In addition, participants who worsened in depression at the three-week follow-up were more likely to report higher perceived stress $(M=21.36, S D=4.27$ vs. $M=14.88, S D=4.91)$ and more likely to report severe stress $(78.2 \%, n=68$ vs. $16.5 \%, n=20)$. In comparison to those participants who improved, those who worsened in stress scores at the three-week follow-up were more likely to report living in an unstable living environment $(32.1 \%, n=27$ vs. $17.9 \%, n=20)$. Furthermore, participants who worsened in stress scores at three-week follow-up were more likely to report higher depression $(M=13.49, S D=4.91$; $M=5.82, S D=4.30)$ and were more likely to report severe depression $(39.8 \%, n=35$ vs. $5.8 \%, n=7)$.

Table 1. Descriptive statistics and group difference analyses between those who worsened and those who improved in depression levels from baseline to follow-up.

\begin{tabular}{|c|c|c|c|c|c|}
\hline & $\begin{array}{l}\text { Worsened Depression } \\
\qquad n=87\end{array}$ & $\begin{array}{l}\text { Improved Depression } \\
\qquad n=121\end{array}$ & \multirow{3}{*}{$\frac{d f}{206}$} & \multirow{3}{*}{$\begin{array}{l}\text { Statistic } \\
t=-1.52\end{array}$} & \multirow{3}{*}{$\begin{array}{c}p \\
0.131\end{array}$} \\
\hline \multirow{2}{*}{$\frac{\text { Demographics }}{\text { Age }}$} & \multicolumn{2}{|c|}{$M(S D)$ or Count (\%) } & & & \\
\hline & $36.6(8.9)$ & $34.6(9.3)$ & & & \\
\hline Gender & & & 1 & $x^{2}=1.53$ & 0.217 \\
\hline Male & $54(62.1 \%)$ & $85(70.2 \%)$ & & & \\
\hline Female & $33(37.9 \%)$ & $36(29.8 \%)$ & & & \\
\hline Race/Ethnicity & & & 3 & $\chi^{2}=1.16$ & 0.763 \\
\hline White, non-Hispanic & $48(55.2 \%)$ & $58(47.9 \%)$ & & & \\
\hline Hispanic & $16(18.4 \%)$ & $26(21.5 \%)$ & & & \\
\hline Black, non-Hispanic & $14(16.1 \%)$ & $24(19.8 \%)$ & & & \\
\hline Other, non-Hispanic & $9(10.3 \%)$ & $13(10.7 \%)$ & & & \\
\hline Education & & & 1 & $\chi^{2}=0.03$ & 0.875 \\
\hline Less than HS & $57(65.5 \%)$ & $78(64.5 \%)$ & & & \\
\hline HS or greater & $30(34.5 \%)$ & $43(35.5 \%)$ & & & \\
\hline Length of Incarceration & & & 1 & $x^{2}=0.11$ & 0.745 \\
\hline Six months or less & $40(46.0 \%)$ & $52(43.7 \%)$ & & & \\
\hline More than six months & $47(54.0 \%)$ & $67(56.3 \%)$ & & & \\
\hline Income at three weeks & & & 1 & $\chi^{2}=9.35$ & 0.002 \\
\hline Less than $\$ 20 \mathrm{~K} /$ year & $76(92.7 \%)$ & $89(76.1 \%)$ & & & \\
\hline Living Situation at three weeks & & & 1 & $\chi^{2}=2.42$ & 0.120 \\
\hline Stable & $57(70.4 \%)$ & $92(80.8 \%)$ & & & \\
\hline Unstable & $24(29.6 \%)$ & $23(20.0 \%)$ & & & \\
\hline Physical health & & & & & \\
\hline Health status at three weeks & & & 1 & $\chi^{2}=4.87$ & 0.027 \\
\hline Poor/fair/good & $22(56.4 \%)$ & $25(34.7 \%)$ & & & \\
\hline Very good/excellent & $17(43.6 \%)$ & $47(65.3 \%)$ & & & \\
\hline Stress & & & & & \\
\hline PSS score at baseline & $23.37(6.31)$ & $20.83(5.89)$ & 206 & $t=-2.97$ & 0.003 \\
\hline PSS score at three weeks & $21.36(4.27)$ & $14.88(4.91)$ & 206 & $t=-9.91$ & $<0.001$ \\
\hline Change in PSS score & $-2.01(6.78)$ & $-5.96(7.44)$ & 206 & $t=-3.92$ & $<0.001$ \\
\hline Stress level at baseline & & & 2 & $\chi^{2}=10.98$ & 0.004 \\
\hline None (0-13) & $5(5.7 \%)$ & $9(7.4 \%)$ & & & \\
\hline Mild (14-19) & $12(13.8 \%)$ & $40(33.1 \%)$ & & & \\
\hline Severe $(20+)$ & $70(80.5 \%)$ & $72(59.5 \%)$ & & & \\
\hline Stress level at three weeks & & & 2 & $\chi^{2}=81.25$ & $<0.001$ \\
\hline None $(0-13)$ & $3(3.4 \%)$ & $42(34.7 \%)$ & & & \\
\hline Mild (14-19) & $16(18.4 \%)$ & $59(48.8 \%)$ & & & \\
\hline Severe $(20+)$ & $68(78.2 \%)$ & $20(16.5 \%)$ & & & \\
\hline
\end{tabular}


Table 2. Descriptive statistics and group difference analyses between those who worsened and those who improved in stress levels from baseline to follow-up.

\begin{tabular}{|c|c|c|c|c|c|}
\hline \multirow[b]{2}{*}{ Demographics } & Worsened Stress $n=88$ & Improved Stress $n=120$ & \multirow[b]{2}{*}{$d f$} & \multirow[b]{2}{*}{ Statistic } & \multirow[b]{2}{*}{$p$} \\
\hline & \multicolumn{2}{|c|}{$M(S D)$ or Count (\%) } & & & \\
\hline Age & $34.8(8.9)$ & $35.9(9.4)$ & 206 & $t=0.88$ & 0.379 \\
\hline Gender & & & 1 & $x^{2}=1.29$ & 0.256 \\
\hline Male & $55(62.5 \%)$ & $84(70.0 \%)$ & & & \\
\hline Female & $33(37.5 \%)$ & $36(30.0 \%)$ & & & \\
\hline Race/Ethnicity & & & 3 & $\chi^{2}=5.99$ & 0.112 \\
\hline White, non-Hispanic & $49(55.7 \%)$ & $57(47.5 \%)$ & & & \\
\hline Hispanic & $21(23.9 \%)$ & $21(17.5 \%)$ & & & \\
\hline Black, non-Hispanic & $10(11.4 \%)$ & $28(23.3 \%)$ & & & \\
\hline Other, non-Hispanic & $8(9.1 \%)$ & $14(11.7 \%)$ & & & \\
\hline Education & & & 1 & $\chi^{2}=0.31$ & 0.579 \\
\hline Less than HS & $59(67.0 \%)$ & $76(63.3 \%)$ & & & \\
\hline HS or greater & $29(33.0 \%)$ & $44(36.7 \%)$ & & & \\
\hline Length of Incarceration & & & 1 & $\chi^{2}=0.59$ & 0.444 \\
\hline Six months or less & $42(47.7 \%)$ & $50(42.4 \%)$ & & & \\
\hline More than six months & $46(52.3 \%)$ & $68(57.6 \%)$ & & & \\
\hline Income at three weeks & & & 1 & $\chi^{2}=2.97$ & 0.085 \\
\hline Less than $\$ 20 \mathrm{~K} /$ year & $64(72.7 \%)$ & $84(70.0 \%)$ & & & \\
\hline Living Situation at three weeks & & & 1 & $\chi^{2}=5.37$ & 0.020 \\
\hline Stable & $57(67.9 \%)$ & $92(82.1 \%)$ & & & \\
\hline Unstable & $27(32.1 \%)$ & $20(17.9 \%)$ & & & \\
\hline Physical health & & & & & \\
\hline Health status at three weeks & & & 1 & $\chi^{2}=0.87$ & 0.352 \\
\hline Poor/fair/good & $21(47.7 \%)$ & $26(38.8 \%)$ & & & \\
\hline Very good/excellent & $23(52.3 \%)$ & $41(61.2 \%)$ & & & \\
\hline Depression & & & & & \\
\hline CES-D-10 score at baseline & $14.64(6.60)$ & $10.71(5.56)$ & $168^{*}$ & $t=-4.53$ & $<0.001$ \\
\hline CES-D-10 score at three weeks & $13.49(4.91)$ & $5.82(4.30)$ & 206 & $t=-11.97$ & $<0.001$ \\
\hline Change in CES & $-1.15(6.83)$ & $-4.89(6.36)$ & 206 & $t=-4.06$ & 0.001 \\
\hline Depression level at baseline & & & 2 & $x^{2}=13.91$ & 0.001 \\
\hline None $(0-9)$ & $21(23.9 \%)$ & $54(45.0 \%)$ & & & \\
\hline Mild (10-14) & $27(30.7 \%)$ & $38(31.7 \%)$ & & & \\
\hline Severe $(15+)$ & $40(45.5 \%)$ & $28(23.3 \%)$ & & & \\
\hline Depression level at three weeks & & & 2 & $x^{2}=79.65$ & $<0.001$ \\
\hline None $(0-9)$ & $20(22.7 \%)$ & $101(84.2 \%)$ & & & \\
\hline Mild (10-14) & $33(37.5 \%)$ & $12(10.0 \%)$ & & & \\
\hline Severe (15+) & $35(39.8 \%)$ & $7(5.8 \%)$ & & & \\
\hline
\end{tabular}

$n=208$; CES-D-10 = 10-item Center for Epidemiologic Studies Depression Scale; ${ }^{*} t$-test with unequal variance used.

\section{Discussion}

This study examined changes in levels of depression and stress among prison inmates during and after incarceration in the U.S. Consistent with our hypothesis, we found that the majority of participant's level of depression and/or stress improved post-release. However, there was a sizable minority of inmates who had an increase in symptoms (30.8\% for depression and $29.8 \%$ for stress). This finding suggests that environmental stressors may be worse in the community than in prison or that post-release reintegration may be particularly challenging for some inmates.

Several studies have noted that for some inmates physical and psychological health may be positively influenced by being in prison due to the structural systems in place that provide inmates with consistent access to shelter, food, exercise, education and health care [18-20]. Furthermore, it has been suggested that for some inmates prison may serve as a refuge from the high rates of substance use or violence found within their communities. It has also been argued that incarceration may be a protective factor against mortality for some inmates whose life expectancy may be shorter in their 
communities due to detrimental environmental factors in comparison to the conditions provided within some prison facilities [21].

In the general U.S. population, the average CES-D-10 and PSS scores are 7-9 and 13-14, respectively [15,22]. Our sample reported much higher levels of depression and stress both before and after release from prison than non-incarcerated persons. The heightened depression and stress levels after release from prison may be associated with initial difficulties during the reintegration process, such as a lack of social support, financial issues, and poor coping styles [23]. An Australian study by Shinkfield and Graffam (2009) on the variables influencing successful reintegration after prison found that mean ratings of psychological health were significantly lower at one to four weeks after release than at pre-release and three to four months post-release among their participants, which may have been associated with unmet expectations or greater problems than anticipated after prison release. Financial issues may have also contributed to feelings of depression and stress, especially since participants in the Australian study tended to be underemployed at one to four weeks after release and employed only $33 \%$ of the days worked by a typical worker [24].

Our findings suggest that interventions need to be developed and tested that not only address depression and stress levels while inmates are still incarcerated but also need to occur immediately following incarceration in order to attend to changes in depression and stress levels post-incarceration, especially for those individuals who get worse. Meditation-based interventions (e.g., transcendental meditation, mindfulness-based stress reduction, and 10-day Vipassana retreats) have been shown to be effective in enhancing psychological well-being and decreasing substance use and recidivism among correctional populations [25]. It is quite possible that mindfulness/meditation-based techniques taught to inmates prior to release and then again as a booster follow-up session post-release may help to reduce their depression and stress levels during and after incarceration which may in turn assist them during the re-integration process and to prevent repeat incarcerations.

The current study has some limitations that are important to highlight. First, although our sample included both men and women, our findings may not generalize to all incarcerated populations in the rest of the U.S. or internationally. Second, the results are based on cross-sectional data and suggestions to intervene on depression or stress aimed at enhancing mental health problems would need to be examined longitudinally. Third, we examined depression and stress levels in the current study but we did not investigate specific mental health problems, such as major depressive disorder or post-traumatic stress disorder. Future studies should consider looking at potential changes in specific mental health concerns among inmates before and after being released from prison or jail. Fourth, we did not control for mental health treatment that inmates may have been receiving while incarcerated or afterwards. Finally, the time period in which we assessed levels of depression and stress (eight weeks prior to and three weeks after release from prison) may have impacted our findings. Different time points (e.g., three, six, or twelve months) in which levels of depression and stress are measured is important for future research to assess. It is quite possible that depression and stress levels may change the longer an individual is in or out of prison or jail.

\section{Conclusions}

Although this study has limitations, its major strength is that it is the first study to our knowledge to examine changes in depression and stress levels during and after incarceration in the U.S. This is particularly important given that a recent systematic review that provides prevalence estimates of psychiatric disorders from inmates in 19 U.S. state prisons found that as many as $29 \%$ and $49 \%$ of inmates suffer from major depression and posttraumatic stress disorder, respectively [26]. Future research is needed to address depression and stress levels among inmates for a healthier transition back into the community and to prevent re-incarcerations.

Acknowledgments: We would like to express our appreciation to the Rhode Island Department of Corrections for their support of this research project. We are especially grateful to the women and men who participated in this study. Preliminary data from this research were presented at the 121st Annual Meeting of the American 
Psychological Association in Honolulu, Hawaii. This research was supported by a grant from the National Institutes of Health (R01 DA024093) to Jennifer Clarke. ClinicalTrials.gov Identifier: NCT01122589.

Author Contributions: Jacob J. van den Berg was the primary writer of the manuscript. Mary B. Roberts organized the data and conducted the statistical analysis. Beth C. Bock, Rosemarie A. Martin, L.A.R. Stein, Arthur R. McGovern, and Jennifer G. Clarke all developed the study design. Donna R. Parker and Sarah Hart Shuford provided feedback on the drafted manuscript. All authors have read and approved the final manuscript.

Conflicts of Interest: The authors declare no conflict of interest.

\section{References}

1. National Research Council. The Growth of Incarceration in the United States: Exploring Causes and Consequences. Committee on Causes and Consequences of High. Rates of Incarceration; Travis, J., Western, B., Redburn, S., Eds.; The National Academies Press: Washington, DC, USA, 2014; p. 2.

2. Human Rights Watch. U.S. Prisons and Offenders with Mental Illness. Available online: http:/ / www.hrw.org/reports/2003/usa1003/usa1003.pdf (accessed on 3 November 2015).

3. United States Department of Justice, Office of Justice Programs. Mental Health Problems of Prison and Jail Inmates. Available online: http://www.bjs.gov/content/pub/pdf/mhppji.pdf (accessed on 3 November 2015).

4. Treatment Advocacy Center. More Mentally III Persons are in Jails and Prisons than Hospitals: A Survey of the States. Available online: http://www.treatmentadvocacycenter.org/storage/documents/final_jails _v_hospitals_study.pdf (accessed on 3 November 2015).

5. World Health Organization. Hot Topics: Depression. Available online: http://www.who.int/topics/ depression/en/ (accessed on 3 November 2015).

6. Lazarus, R.S.; Folkman, S. Stress, Appraisal, and Coping; Springer: New York, NY, USA; 1984; p. 19.

7. Travis, J.; Waul, M. Prisoners Once Removed: The Impact of Incarceration and Reentry on Children, Families, and Communities; The Urban Institute Press: Washington, DC, USA; 2004; pp. 33-66.

8. National Institute of Mental Health. What is Depression. Available online: http://www.nimh.nih.gov/ health/topics/depression/index.shtml (accessed on 3 November 2015).

9. Shalev, A.Y.; Freedman, S.; Perry, T.; Brandes, D.; Sahar, T.; Orr, S.P.; Pitman, R.K. Prospective study of posttraumatic stress disorder and depression following trauma. Am. J. Psychiatry 1998, 155, $630-637$. [CrossRef] [PubMed]

10. Schneiderman, N.; Ironson, G.; Siegel, S.D. Stress and health: Psychological, behavioral, and biological determinants. Annu. Rev. Clin. Psychol. 2005, 1, 607-628. [CrossRef] [PubMed]

11. Tosevski, D.L.; Milovancevic, M.P. Stressful live events and physical health. Curr. Opin. Psychiatry 2006, 19, 184-189. [CrossRef] [PubMed]

12. Cohen, S.; Janicki-Deverts, D.; Miller, G.E. Psychological stress and disease. JAMA 2007, 298, $1685-1687$. [CrossRef] [PubMed]

13. Clarke, J.G.; Martin, R.A.; Stein, L.A.R.; Lopes, C.E.; Mello, J.; Friedman, P.; Bock, B. Working Inside for Smoking Elimination (Project W.I.S.E.) study design and rationale to prevent return to smoking after release from a smoke free prison. BMC Public Health 2011, 11, 767. [CrossRef] [PubMed]

14. Clarke, J.G.; Stein, L.A.R.; Martin, R.A.; Martin, S.A.; Parker, D.; Lopes, C.E.; McGovern, A.R.; Simon, R.; Roberts, M.; Friedman, P.; et al. Forced abstinence: Not enough for smoking cessation. JAMA Intern. Med. 2013, 173, 789-794. [CrossRef] [PubMed]

15. Andresen, E.M.; Malmgren, J.A.; Carter, W.B.; Patrick, D.L. Screening for depression in well older adults: Evaluation of a short form of the CES-D (Center for Epidemiologic Studies Depression Scale). Am. J. Prev. Med. 1994, 10, 77-84. [PubMed]

16. Miller, W.C.; Anton, H.A.; Townson, A.F. Measurement properties of the CESD scale among individuals with spinal cord injury. Spinal Cord 2008, 46, 287-292. [CrossRef] [PubMed]

17. Cohen, S.; Kamarck, T.; Mermelstein, R. A global measure of perceived stress. J. Health Soc. Behav. 1983, 24, 385-396. [CrossRef] [PubMed]

18. Dumont, D.M.; Brockmann, B.; Dickman, S.; Alexander, N.; Rich, J.D. Public health and the epidemic of incarceration. Annu. Rev. Public Health 2012, 33, 325-339. [CrossRef] [PubMed] 
19. Spaulding, A.C.; Seals, R.M.; McCallum, V.A.; Perez, S.D.; Brzozowski, A.K.; Steenland, N.K. Prisoner survival inside and outside of the institution: Implications for health-care planning. Am. J. Epidemiol. 2011, 173, 479-487. [CrossRef] [PubMed]

20. Patterson, E.J. Incarcerating death: Mortality in U.S. state correctional facilities, 1985-1998. Demography 2010, 47, 587-607. [CrossRef] [PubMed]

21. Rosen, D.L.; Wohl, D.A.; Schoenbach, V.J. All-cause and cause-specific mortality among black and white North Carolina state prisoners, 1995-2005. Ann. Epidemiol. 2011, 21, 719-726. [CrossRef] [PubMed]

22. Cohen, S.; Williamson, G.M. Perceived stress in a probability sample of the United States. In The Social Psychology Health; Spacapan, S., Oskamp, S., Eds.; SAGE Publishing: Newbury Park, CA, USA, 1988; pp. 31-67.

23. Fogel, C.I. Hard time: The stressful nature of incarceration for women. Issues Ment. Health Nurs. 1993, 14, 367-377. [CrossRef] [PubMed]

24. Shinkfield, A.J.; Graffam, J. Community reintegration of ex-prisoners: Type and degree of change in variables influencing successful reintegration. Int. J. Offender Ther. Comp. Criminol. 2009, 53, 29-42. [CrossRef] [PubMed]

25. Himelstein, S. Meditation research: The state of the art in correctional settings. Int. J. Offender Ther. Comp. Criminol. 2011, 55, 646-661. [CrossRef] [PubMed]

26. Prins, S.J. Prevalence of mental illnesses in U.S. state prisons: A systematic review. Psychiatr. Serv. 2014, 65, 862-872. [CrossRef] [PubMed]

(C) 2016 by the authors; licensee MDPI, Basel, Switzerland. This article is an open access article distributed under the terms and conditions of the Creative Commons by Attribution (CC-BY) license (http://creativecommons.org/licenses/by/4.0/). 